\title{
Desenho e Avaliação do Impacto de uma Ação de Formação em Suporte Básico de Vida nas Escolas
}

\section{Design and Evaluation of the Impact of a Basic Life Support Training in Schools}

Ana Rafaela Marques Ribeiro 1 , Juliana Marília Pereira de Sá2 ${ }^{2}$ Ricardo Tjeng ${ }^{3}$

Autor Correspondente/Corresponding Author: Ana Rafaela Marques Ribeiro [rafaelamarquesribeiro94@gmail.com] Rua das Águas Santas, 125, 6300-808 Guarda, Portugal ORCID iD: 0000-0001-9659-6686

\section{RESUMO}

INTRODUÇÃO: O tempo entre o estabelecimento da paragem cardiorrespiratória e o início do suporte básico de vida é fundamental; encurtar este tempo é a melhor forma de aumentar a probabilidade de sobrevivência da vítima. As guidelines internacionais recomendam o ensino de reanimação cardiopulmonar nas escolas. Este trabalho pretende contribuir para a construção de programas de educação sobre suporte básico de vida nas escolas.

MATERIAL E MÉTODOS: Foram incluídos no estudo cinquenta e cinco alunos do $8^{\circ}$ ano. Um grupo de 24 alunos participou numa formação teórico-prática de 60 minutos, enquanto que um segundo grupo de 28 alunos respondeu apenas a inquéritos. Ambos os grupos responderam a um inquérito inicial antes da formação e a um inquérito de acompanhamento um mês depois. $\bigcirc$ grupo que recebeu formação respondeu também imediatamente após esta. $\bigcirc$ inquérito consistiu em perguntas de escolha múltipla sobre conhecimento teórico, autoavaliação da capacidade de realização de suporte básico de vida e medo autopercebido de ser o primeiro a dar resposta perante uma paragem cardiorrespiratória.

RESULTADOS: No grupo que recebeu formação, antes de esta decorrer, observa-se que a média de respostas corretas, valorizadas entre 0 e 9, era de 4,29. Um mês depois a média foi 7,67 para este grupo e 4,43 no grupo que não recebeu formação. No grupo que recebeu formação, a capacidade de agir aumentou significativamente e o medo diminuiu significativamente.

CONCLUSÃO: Uma sessão de treino em suporte básico de vida tem impacto em capacitar os alunos a agir corretamente perante uma paragem cardiorrespiratória. O conhecimento parece manter-se ao longo do tempo.

PALAVRAS-CHAVE: Educação em Saúde; Escolas; Portugal; Ressuscitação cardiopulmonar/Ensino

1. Aluna do Mestrado Integrado em Medicina da Faculdade de Ciências da Saúde da Universidade da Beira Interior, Covilhã, Portugal. 2. Mestrado Integrado em Medicina, Interna de Formação Específica em Medicina Interna do Centro Hospitalar Cova da Beira, Covilhã, Portugal. 3. Licenciatura em Medicina, Assistente Hospitalar em Medicina Interna do Centro Hospitalar Cova da Beira, Covilhã, Portugal. 


\section{ABSTRACT}

INTRODUCTION: The time between the establishment of the cardiorespiratory arrest and the beginning of basic life support is fundamental; shortening this time is the best way to increase the probability of the victim's survival. International guidelines recommend teaching cardiopulmonary resuscitation in schools. This work intends to contribute to the construction of basic life support education programs in schools.

MATERIAL AND METHODS: Fifty-five students from 8th grade were included in the study. A group of 24 students participated in a 60-minute theoretical-practical training, while a second group of 28 students answered only to the surveys. Both groups responded to an initial survey prior to training and to a follow-up survey one month later. The group that received training also responded immediately after this. The survey consisted of multiple-choice questions about theoretical knowledge, self-assessment of the ability to perform basic life support and self-perceived fear of being the first to respond to a cardiorespiratory arrest.

RESULTS: In the group that received training, before this happens, it was observed that the average of correct answers, valued between 0 and 9 , was 4.29. One month later the mean was 7.67 for this group and 4.43 for the non-trained group. In the training group, the ability to act increased significantly and the fear decreased significantly.

CONCLUSION: A training session in basic life support has an impact on enabling students to act correctly before a cardiorespiratory arrest. Knowledge seems to keep up over time.

KEYWORDS: Cardiopulmonary Resuscitation/education; Health Education; Portugal; Schools

\section{INTRODUÇÃO}

O tempo entre o início de uma paragem cardiorrespiratória (PCR) e a prestação de cuidados é fundamental; encurtar esse tempo aumenta a probabilidade de sobrevivência da vítima. ${ }^{1}$ Os níveis de conhecimento de SBV da população portuguesa são baixos. ${ }^{2}$ Em Portugal, a taxa de sobrevivência perante uma paragem cardiorrespiratória extra-hospitalar (PCREH) é de 3\%, o que pode estar associado à falta de preparação da sociedade civil para atuar. $^{3}$

A American Heart Association (AHA) e a Organização Mundial da Saúde (OMS) recomendam o ensino de reanimação cardiopulmonar (RCP) nas escolas. ${ }^{4,5}$ Os alunos são o grupo de atuação preferencial, de fácil acesso e motivação. A implementação de um programa de formação em suporte básico de vida (SBV) nas escolas permitirá: a aprendizagem de um grande número de crianças, que, com o tempo, aumentará a proporção de adultos treinados; aumentar a consciencialização da importância de agir perante uma PCR; treino quando a aprendizagem é a principal atividade; exposição da informação a um segundo nível de aprendizes em casa. ${ }^{6}$

Os objetivos deste estudo foram desenvolver uma ação de formação sobre SBV, avaliar o seu impacto em alunos do $8^{\circ}$ ano, estudar o seu efeito ao longo do tempo e comparar alunos que receberam formação com alunos que não receberam. Ainda não existe um programa estruturado para o ensino desta técnica em Portugal, pelo que este trabalho pretende contribuir para esse efeito.

\section{MÉTODOS}

Este estudo é de tipo coorte prospetivo e foi desenvolvido na Escola Secundária Quinta das Palmeiras/3, na Covilhã, no ano de 2018. Procurou-se que os participantes tivessem entre 13-15 anos, pois o condicionamento físico já é suficiente para fornecer SBV.? Os alunos incluídos no projeto pertenciam às turmas do $8^{\circ}$ ano selecionadas pela escola. Foram divididos em dois grupos, um de 25 alunos que viria a receber formação em SBV e outro de 30 alunos que não viria a receber formação.

O protocolo de investigação foi aprovado pelo Conselho Diretivo da escola e pela Comissão de Ética da Universidade da Beira Interior. Apenas participaram no estudo alunos com consentimento informado assinado pelos encarregados de educação.

Para colheita de dados foi aplicado um inquérito com perguntas de escolha múltipla desenvolvido pelos investigadores. $\bigcirc$ inquérito continha 9 perguntas sobre conhecimentos teóricos de SBV. Às respostas certas foi atribuída a classificação de um ponto. A retenção do conhecimento teórico foi analisada através da soma dos pontos. As questões 10 e 11 abordavam a autoavaliação da capacidade de realização de SBV e o medo autopercebido de ser o primeiro a dar resposta perante uma PCR, respetivamente, e foram tratadas como variáveis em escala de Likert. Um teste piloto foi aplicado a cinco adolescentes, sendo efetuadas as adaptações necessárias. $\bigcirc$ grupo que participou na formação respondeu ao inquérito em três momentos: antes da sessão de treino 
(Qi), imediatamente após (Q2i), e um mês depois (Q2t). O grupo que não recebeu formação respondeu aquando de Qi e Q2t.

O conteúdo da formação foi baseado nas guidelines internacionais para esta matéria.8,9 A formadora foi uma estudante de medicina do $5^{\circ}$ ano, autora do estudo. Cada sessão foi dividida numa componente expositiva teórica de 20 minutos e numa componente prática de 40 minutos. Os alunos treinaram o pedido de socorro, simulando uma chamada para o 112. Todos os alunos realizaram manobras de SBV num manequim. Procurou-se dar feedback acerca do desempenho da RCP de cada um, nomeadamente ao nível da frequência e profundidade das compressões torácicas e retorno do tórax. Salientou-se o facto de as compressões serem decisivas, mesmo na ausência de ventilações. ${ }^{10,11}$

\section{ANÁLISE ESTATÍ́STICA}

Os dados foram analisados usando o software Statistical Package for Social Sciences (SPSS) versão 25.0. A significância estatística foi fixada em 5\%.

Foi atribuído zero pontos aos itens de 1-9 não respondidos.

Para analisar as variáveis nominais optou-se pelo teste do qui-quadrado. Para estudar a evolução do grupo que recebeu formação e comparar os grupos foi utilizado o teste não paramétrico de Mann-Whitney. Para relacionar a autoavaliação da capacidade de realização de SBV e o medo autopercebido de ser o primeiro a dar resposta perante uma PCR com a retenção dos conhecimentos foi aplicado o coeficiente de correlação de Pearson.

\section{RESULTADOS}

O inquérito foi respondido por 24 alunos que receberam formação, $54 \%$ dos quais eram do sexo feminino, 92\% tinham 14 anos e os restantes 8\% tinham 15 anos. No grupo que não recebeu formação, o inquérito foi respondido por 28 alunos, dos quais também 54\% eram do sexo feminino, $96 \%$ tinham 14 anos e os restantes 4\% tinham 15 anos.

Verificou-se que, no início do estudo os dois grupos não apresentaram diferenças estatisticamente significativas entre si, relativamente ao sexo, à idade, ao conhecimento teórico sobre SBV (com exceção da questão 6), à autoavaliação da capacidade de realização de SBV e ao medo autopercebido de ser o primeiro a dar resposta perante uma PCR.

\section{EVOLUÇÃO DO GRUPO QUE RECEBEU FORMAÇÃO}

Na distribuição do total de respostas corretas entre cada par de momentos, observa-se que a média do total de respostas corretas aumenta de Qi $(M=4,29)$ para Q2i $(M=7,63)$ de forma estatisticamente significativa $(U=18,0 ; \quad p<0,001)$, aumentando depois ligeiramente para Q2t $(M=7,67)$ mas de forma não significativa $(U=275,5 ; p=0,790)$.

A média das respostas a $P 10$, aumenta de $Q \mathbf{~}(M=2,38)$ para Q2i $(M=3,83)$ de forma estatisticamente significativa $(U=67,5 ; p<0,001)$, diminuindo depois para Q2t $(M=3,46)$ de forma também significativa $(U=198,5$; $p=0,035)$.

A média das respostas a P11 diminui de Qi $(M=2,70)$ para Q2i $(M=2,08)$ de forma estatisticamente significativa $(U=165,0 ; p=0,011)$, diminuindo depois ligeiramente para Q2t $(M=1,96)$, mas de forma não significativa $(U=249,0 ; p=0,523)$.

\section{COMPARAÇÃO ENTRE O GRUPO QUE RECEBEU FORMAÇÃO E O GRUPO QUE NÃO RECEBEU UM MÊS APÓS A SESSÃO DE TREINO}

A média do total de respostas corretas é superior para o grupo que recebeu formação $(M=7,67)$ face ao grupo que não recebeu $(M=4,43)$ (Tabela 1$)$, sendo as diferenças estatisticamente significativas $(U=36,0 ; p<0,001)$.

Perante a questão 10, 58\% dos alunos do grupo que recebeu formação afirmaram estar preparados para agir, enquanto que apenas 14\% do grupo que não recebeu formação deu a mesma resposta. A média das respostas nesta pergunta é superior para o grupo que recebeu formação $(M=3,46)$ e inferior para o grupo que não recebeu $(M=2,64)$, sendo as diferenças estatisticamente significativas $(U=159,5 ; p=0,001)$.

Perante a questão 11, 26\% dos alunos do grupo que recebeu formação afirmaram não ter medo de agir, enquanto que apenas $11 \%$ do grupo que não recebeu formação deu a mesma resposta. A média das respostas é inferior para o grupo que recebeu formação $(M=1,96)$ e superior para o grupo que não recebeu $(M=2,57)$, sendo as diferenças estatisticamente significativas $(U=197,5$; $p=0,012$ ).

\section{CONFIANÇA E RETENÇÃO DOS CONHECIMENTOS}

Na totalidade dos dados recolhidos, verifica-se que uma maior retenção dos conhecimentos está associada a uma melhor autoavaliação da capacidade de realizar 
TABELA 1. Estatística descritiva: Relações entre as questões P1 a P9 nos três momentos (Qi, Q2i e Q2t), para o Grupo que recebeu Formação.

\begin{tabular}{|c|c|c|c|c|}
\hline & Momento & $\mathrm{N}$ & $\begin{array}{c}\% \\
\text { corretas }\end{array}$ & $\begin{array}{l}\text { Desvio } \\
\text { padrão }\end{array}$ \\
\hline \multirow{3}{*}{$\begin{array}{l}\text { P1. Cadeia de } \\
\text { sobrevivência }\end{array}$} & Qi & 24 & $87,5 \%$ & $33,8 \%$ \\
\hline & Q2i & 24 & $16,7 \%$ & $38,1 \%$ \\
\hline & Q2t & 24 & $50,0 \%$ & $51,1 \%$ \\
\hline \multirow{3}{*}{$\begin{array}{l}\text { P2. Avaliar as condições } \\
\text { de segurança }\end{array}$} & Qi & 23 & $17,4 \%$ & $38,8 \%$ \\
\hline & Q2i & 24 & $87,5 \%$ & $33,8 \%$ \\
\hline & Q2t & 24 & $83,3 \%$ & $38,1 \%$ \\
\hline \multirow{3}{*}{$\begin{array}{l}\text { P3. Avaliar o estado } \\
\text { de consciência }\end{array}$} & Qi & 24 & $62,5 \%$ & $49,5 \%$ \\
\hline & Q2i & 24 & $91,7 \%$ & $28,2 \%$ \\
\hline & Q2t & 23 & $73,9 \%$ & $44,9 \%$ \\
\hline \multirow{3}{*}{$\begin{array}{l}\text { P4. Permeabilizar a via } \\
\text { aérea }\end{array}$} & Qi & 24 & $25,0 \%$ & $44,2 \%$ \\
\hline & Q2i & 24 & $54,2 \%$ & $50,9 \%$ \\
\hline & Q2t & 24 & $66,7 \%$ & $48,2 \%$ \\
\hline \multirow{3}{*}{ P5. Avaliar respiração } & Qi & 23 & $69,6 \%$ & $47,0 \%$ \\
\hline & Q2i & 24 & $95,8 \%$ & $20,4 \%$ \\
\hline & Q2t & 24 & $83,3 \%$ & $38,1 \%$ \\
\hline \multirow{3}{*}{ P6. Quando ligar 112} & Qi & 24 & $20,8 \%$ & $41,5 \%$ \\
\hline & Q2i & 24 & $87,5 \%$ & $33,8 \%$ \\
\hline & Q2t & 24 & $91,7 \%$ & $28,2 \%$ \\
\hline \multirow{3}{*}{$\begin{array}{l}\text { P7. Realizar manobras } \\
\text { de SBV }\end{array}$} & Qi & 23 & $4,3 \%$ & $20,9 \%$ \\
\hline & Q2i & 24 & $87,5 \%$ & $33,8 \%$ \\
\hline & Q2t & 24 & $54,2 \%$ & $50,9 \%$ \\
\hline \multirow{3}{*}{ P8. Manter SBV } & Qi & 24 & $41,7 \%$ & $50,4 \%$ \\
\hline & Q2i & 23 & $78,3 \%$ & $42,2 \%$ \\
\hline & Q2t & 23 & $78,3 \%$ & $42,2 \%$ \\
\hline \multirow{3}{*}{ P9. Como ligar 112} & Qi & 24 & $83,3 \%$ & $38,1 \%$ \\
\hline & Q2i & 24 & $100,0 \%$ & $0,0 \%$ \\
\hline & Q2t & 24 & $95,8 \%$ & $20,4 \%$ \\
\hline
\end{tabular}

SBV ( $r=0,504 ; p<0,001)$, sendo esta uma relação moderada positiva, e a um menor medo autopercebido de ser o primeiro a dar resposta perante uma PCR ( $r=-0,324$; $p<0,001)$, sendo esta uma relação baixa negativa.

\section{DISCUSSÃO \\ CONHECIMENTO TEÓRICO}

O conhecimento de SBV dos estudantes do ensino básico é baixo, o que reflete a incipiente cultura de emergência médica da população portuguesa em geral. Antes da sessão de treino, em 9 perguntas, a média de respostas corretas no inquérito do grupo que recebeu formação foi 4,29 e a média do grupo que não recebeu foi 4,61.

Uma sessão de treino de 60 minutos teve impacto em capacitar os alunos para agir corretamente perante uma PCR. O conhecimento dos alunos aumentou em todos os itens, tanto logo após a formação, como um mês depois, sendo superior comparativamente ao grupo que não recebeu, salvo no reconhecimento do primeiro elo da cadeia de sobrevivência, não podendo este facto ser fundamentado pelas características da investigação. "Como ligar 112" teve uma taxa de acertados elevada, possivelmente devido ao nível de dificuldade de a pergunta ser baixo. Um mês depois, os alunos mantinham um bom nível de conhecimento em quase todos os itens analisados e conhecimento superior ao do grupo que não recebeu formação. Não houve alterações significativas nos itens analisados no grupo que não recebeu formação.

\section{CONFIANÇA PARA AGIR PERANTE UMA PCR}

Apesar de o medo e a autoconfiança não terem sido diretamente abordados na formação, os alunos relataram sentir-se melhor preparados para poder agir. Um mês depois, verifica-se que a capacidade de realizar SBV do grupo que recebeu formação aumentou e o medo diminuiu. A resposta mais prevalente foi "Estou bem preparado para poder agir", embora a maioria assuma medo leve.

Bonh et al, ${ }^{12}$ numa revisão de literatura, identificaram como principais motivos para que os cidadãos não iniciem manobras de SBV: a falha no reconhecimento da PCR, a falta de conhecimentos sobre SBV, o medo de fazer algo errado e o medo de infeção. A possibilidade de treino em ambiente de simulação permite a diminuição da ansiedade face a uma situação real. Em idade escolar, as habilidades psicomotoras são adquiridas de maneira mais natural e fácil, o que permite reduzir o medo de cometer erros. Crianças em idade escolar têm uma abordagem menos inibida para o treino de RCP, neste sentido, o ensino de SBV permite-Ihes aprender a ter sentido de responsabilidade social, assim como, adquirir competências sociais 5 . Por outro lado, a não obrigatoriedade de fazer ventilações tem um papel de relevo, na medida em que diminui a relutância em iniciar manobras de SBV em desconhecidos.

\section{IMPACTO DE UM PROGRAMA DE FORMAÇÃO EM SBV NAS ESCOLAS}

Considerando o impacto da formação iniciada em crianças nos futuros adultos, podemos perspetivar uma sociedade repleta de cidadãos que dominam as habilidades relacionadas com RCP. Tal possibilitaria grandes ganhos em saúde ao nível da prevenção da morte súbita cardíaca. Em Portugal ocorrem cerca de 10000 casos de PCR por ano, ${ }^{13} 27$ por dia. Entre 2013 e 2014 foram registadas 23347 PCREH associadas a uma taxa de sobrevivência de 4,43\%, enquanto que para o mesmo período, esta taxa foi de 21\% na Holanda e 25\% na 
Noruega. ${ }^{14}$ Esta elevada discrepância denuncia a necessidade de criação de programas de formação em SBV que sejam efetivos e acessíveis ao maior número de pessoas possível.

\section{IMPLEMENTAÇÃO DO ENSINO DE SBV NAS ESCOLAS}

Uma curta sessão de treino de uma hora, como a que decorreu neste estudo, é suficiente para alcançar bons resultados ao nível da aquisição das habilidades e conhecimentos, sendo um período de tempo de fácil inclusão nos currículos escolares.

López et a ${ }^{15}$ consideram que formar os professores pode ser o primeiro passo para implementar o ensino de SBV nas escolas. Dotar as escolas de um corpo pedagógico capaz de ensinar SBV, tem sido considerado tão eficaz como o treino fornecido por profissionais de saúde. ${ }^{16}$ Outros estudos sugerem que os professores sejam treinados por estudantes de medicina. ${ }^{17}$

Neste estudo, a formação dada por uma estudante de medicina foi bem-sucedida. $O$ ensino por estudantes de medicina poderia ser sustentável, mas seriam necessários estudos sobre a motivação destes.

\section{LIMITAÇÕES DO ESTUDO}

A comparação deste estudo com outros semelhantes é dificultada pelo número reduzido de participantes e o pouco tempo para medir os outcomes. Existe algum risco de viés de seleção, porque apenas foi estudada uma escola e um ano escolar.

O efeito a longo prazo de uma sessão de treino não foi avaliado. Também o tempo disponibilizado para a formação pode condicionar os resultados, pois 60 minutos representam metade do tempo recomendado pela OMS. ${ }^{6}$

O estudo apresenta falta de precisão para comparar se houve melhorias no domínio das habilidades práticas, nomeadamente da realização de compressões torácicas, uma vez que a valorização da aprendizagem se levou a cabo mediante um inquérito e não mediante um exercício prático. Não foi avaliada a fiabilidade e consistência do inquérito.

\section{CONCLUSÃO}

Os resultados deste estudo reforçam que a inclusão de ações de formação teórico-práticas de SBV nos currículos escolares pode ser uma mais-valia na capacitação da população leiga na resposta perante uma PCR.
CONFLITOS DE INTERESSE: Os autores declaram não ter qualquer conflito de interesse na realização do presente trabalho.

FONTES DE FINANCIAMENTO: Não houve qualquer fonte de financiamento na realização do presente trabalho.

CONFIDENCIALIDADE DOS DADOS: Os autores declaram ter seguido os protocolos da sua instituição acerca da publicação dos dados de doentes.

PROTEÇÃO DE PESSOAS E ANIMAIS: Os autores declaram que os procedimentos seguidos na elaboração do presente trabalho estão em conformidade com as normas das comissões de investigação clínica e de ética, bem como da declaração de Helsínquia e da Associação Médica Mundial.

PROVENIÊNCIA E REVISÃO POR PARES: Não comissionado; revisão externa por pares.

CONFLICTS OF INTEREST: The authors declare that they have no conflicts of interest.

FINANCIAL SUPPORT: This work has not received any contribution, grant or scholarship.

CONFIDENTIALITY OF DATA: The authors declare that they have followed the protocols of their work center on the publication of data from patients.

PROTECTION OF HUMAN AND ANIMAL SUBJECTS: The authors declare that the procedures followed were in accordance with the regulations of the relevant clinical research ethics committee and with those of the Code of Ethics of the World Medical Association (Declaration of Helsinki).

PROVENANCE AND PEER REVIEW: Not commissioned; externally peer reviewed.

\section{REFERÊNCIAS}

1. Shinozaki K, Nonogi H, Nagao K, Becker L. Strategies to improve cardiac arrest survival: a time to act. Acute Med Surg. 2016;3:61-4. doi: 10.1002/ams2.192.

2. Dixe MA, Gomes J. Conhecimento da população portuguesa sobre suporte básico de vida e disponibilidade para realizar formação. Rev Esc Enf USP. 2015;49:640-9.

3. Noronha N. Apenas 3\% das paragens cardiorrespiratórias sobrevivem. Radio Regional. 2018 Feb 20 [cited 27 November 2018]. Available from: https://radioregional.pt/apenas-3-das-paragens-cardiorrespiratoria-sobrevivem.

4. Tavares A, Pedro N, Urbano J. Ausência de formação em suporte básico de vida pelo cidadão: um problema de saúde pública? Qual a idade certa para iniciar? Rev Port Saúde Pública. 2016;34:101-4.

5. Cave D, Aufderheide T, Beeson J, Ellison A, Gregory A, Hazinski $\mathrm{M}$ et al. Importance and implementation of training in cardiopulmonary resuscitation and automated external defibrillation in schools. Circulation. 2011:123:691-706. doi: 10.1161/ CIR.0b013e31820b5328. 
6. Böttiger BW, Van Aken H. Kids save lives: training school children in cardiopulmonary resuscitation worldwide is now endorsed by the World Health Organization (WHO). Resuscitation. 2015;94:A5-A7. doi: 10.1016/j.resuscitation.2015.07.005.

7. Jones I, Whitfield R, Colquhoun M, Chamberlain D, Vetter N, Newcombe R. At what age can schoolchildren provide effective chest compressions? An observational study from the Heartstart UK Schools Training Programme. BMJ. 2007;334:1201.

8. Travers A, Rea T, Bobrow B, Edelson D, Berg R, Sayre M, et al. Part 4: CPR Overview: 2010 American Heart Association Guidelines for Cardiopulmonary Resuscitation and Emergency Cardiovascular Care. Circulation. 2010;122(18_suppl_3):S676-S684.

9. Monsieurs KG, Nolan JP, Bossaert LL, Greif R, Maconochie IK, Nikolaou NI, et al. ERC Guidelines 2015 Writing Group. European Resuscitation Council Guidelines for Resuscitation 2015: Section 1. Executive summary. Resuscitation. 2015;95:1-80. doi: 10.1016/j.resuscitation.2015.07.038.

10. Nolan J, Soar J, Zideman D, Biarent D, Bossaert L, Deakin C, et al. European Resuscitation Council Guidelines for Resuscitation 2010 Section 1. Executive summary. Resuscitation. 2010;81:1219-76. doi: 10.1016/j.resuscitation.2010.08.021.

11. Svensson L, Bohm K, Castrèn M, Pettersson H, Engerström L, Herlitz J, et al. Compression-Only CPR or Standard CPR in Out-of-Hospital Cardiac Arrest. New Engl J Med. 2010;363:43442. doi: 10.1056/NEJMoa0908991.

12. Bohn A, Van Aken H, Möllhoff T, Wienzek H, Kimmeyer P, Wild E, et al. Teaching resuscitation in schools: annual tuition by trained teachers is effective starting at age 10. A four-year prospective cohort study. Resuscitation. 2012;83:619-25. doi: 10.1016/j.resuscitation.2012.01.020.

13. Dados estatísticos - Fundação Portuguesa Cardiologia [Internet]. Fundação Portuguesa Cardiologia. [cited 3 January 2019]. Available from: http://www.fpcardiologia.pt/atividades/projeto-salva-vidas/dados-estatisticos/.

14. Caldeira P. A sobrevivência da paragem cardiorespiratória e o investimento em iniciativas de intervenção na população [Mestrado em Gestão]. Atlântica: University Higher Institution; 2016.

15. Pichel López M, Martínez-Isasi S, Barcala-Furelos R, Fernández-Méndez F, Vázquez Santamariña D, Sánchez-Santos L, et al. Un primer paso en la enseñanza del soporte vital básico en las escuelas: la formación de los profesores. An Pediatr. 2018;89:265-71. doi: 10.1016/j.anpedi.2017.11.002.

16. Schroeder D, Ecker H, Wingen S, Semeraro F, Böttiger B. "Kids Save Lives" - Wiederbelebungstrainings für Schulkinder. Anaesthesist. 2017;66:589-97. doi: 10.1007/s00101-0170319-z.

17. Toner P, Connolly M, Laverty L, McGrath P, Connolly D, McCluskey D. Teaching basic life support to school children using medical students and teachers in a 'peer-training' model-Results of the 'ABC for life' programme. Resuscitation. 2007;75:169-75. 